\title{
Determination of Safety Distance for Installing GSM Mast in Residential Areas in Nigeria
}

\author{
*11DANLADI, A; GAYA, GK; ALIYU, BM; STEPHEN, M; MICHAEL, Y; \\ NA'IMU, A
}

Department of Pure and Applied Physics, Adamawa State University, Mubi, Nigeria

*E-mail: deshalangs3g@yahoo.com; Phone: +2347063853164

\begin{abstract}
Global System for Mobile Communication (GSM) technology is one of the fastest growing technologies and most demanding application all over the world. But the health implication of its equipment used or installed in residential area has become subject debate among Nigerian. This work, made an attempt to determine the safety distance for installing GSM mast in residential area by measuring power density radiated from the foot of the GSM mast at different distances; 10m, 15m, 20m, 25m, 30m, 35m, 40m, 45m and 50m. Fuzzy logic technique was used to forecast power density measured from the GSM mast as $38.9 \mu \mathrm{W} / \mathrm{m}^{2}, 9.26 \mu \mathrm{W} / \mathrm{m}^{2}, 9.30 \mu \mathrm{W} / \mathrm{m}^{2}, 9.24 \mu \mathrm{W} / \mathrm{m}^{2}$, $2.47 \mu \mathrm{W} / \mathrm{m}^{2}, 2.47 \mu \mathrm{W} / \mathrm{m}^{2}, 2.38 \mu \mathrm{W} / \mathrm{m}^{2}, 2.37 \mu \mathrm{W} / \mathrm{m}^{2}$ and $2.36 \mathrm{e}^{-6} \mu \mathrm{W} / \mathrm{m}^{2}$. Specific Absorption Rate (SAR) is computed as $1.09 \mathrm{e}^{-4} \mathrm{~W} / \mathrm{Kg}, 2.60 \mathrm{e}^{-5} \mathrm{~W} / \mathrm{Kg}, 2.61 \mathrm{e}^{-5} \mathrm{~W} / \mathrm{Kg}, 2.62 \mathrm{e}^{-5} \mathrm{~W} / \mathrm{kg}, 6.94 \mathrm{e}^{-6} \mathrm{~W} / \mathrm{Kg}, 6.69 \mathrm{e}^{-6} \mathrm{~W} / \mathrm{Kg}, 6.66 \mathrm{e}^{-6} / \mathrm{Kg}$ and $6.63 \mathrm{e}^{-6} \mathrm{~W} / \mathrm{Kg}$ from the forecasted power density respectively. The calculated SAR is compared with the standard SAR values, for localize and whole part of the body $(0.08 \mathrm{Kg} / \mathrm{W}$ and $2.00 \mathrm{Kg} / \mathrm{W})$ given by the International Commission on Non Ionizing Radiation Protection (ICNIRP) and found to be far below recommended level. This work also, suggested that, $10 \mathrm{~m}$ is a good distance for installing GSM mast away from residential areas. @JASEM
\end{abstract}

\section{http://dx.doi.org/10.4314/jasem.v20i4.12}

Keywords: Power Density, Fuzzy Logic, Risk, Distance, Specific Absorption Rate and Safety

The introduction of global system for mobile communication (GSM) has significantly solved the problems of communication in Nigeria. However, the health risk of using mobile equipment (ME), living under or near the GSM mast has become a subject of concern among Nigerians. Some groups opined and believed to date that, the non-ionizing radiation from GSM mast is inimical to health. That is, living near the mast for a long period of time can cause several diseases such as cancer, persistent headaches, destroy reproductive organ and damage brain (Dariusz et al,, 2002; Santini et al., 2003; Lennart et al., 2007; Akintola et al., 2009; Shangchen et al., 2009). In contrast, some groups like International Commission on Non Ionizing Radiation (ICNIRP), Mobile Manufacturer Forum (MMF) that manufactures ME and GSM operators across the globe insist that radiation from GSM mast does not have sufficient energy to cause discernible effect on human body (Shalangwa, 2010; Mamilus and Anthoney, 2012). Many literature also reported that long term exposure of non-ionizing radiation may have effect on a specific part of a body like eyes (Hyland, 2000), brain (Leif, 2003; Sahar and Jabir, 2013), testes and pregnant women (Person, 1997 and Thomas et al., 2002). This is because, these parts of the human body have relatively insufficient blood to dissipate excessive heat generated due to non-ionizing radiation. Quite a number of researches have been carried out on this issue. For example, (Thomas et al., 2002 and Lennart et al, 2007), but mostly conducted in different geographical areas. The methods mostly used to assess the radiation include, regression and correlation (Akintola et al., 2009; Shalangwa, 2010; Shalangwa, 2011; Mamilus and Anthoney, 2012). This work proposes to determine the safety distance for installing GSM mast in residential area with the following objective; to measure power density from the foot of GSM mast at different distances (10m $50 \mathrm{~m}$ ), develop simulation model of fuzzy logic to forecast the amount of the power density measured, from the previous and actual power density measured, use the values of the forecasted power density and compute the SAR then, compare the calculated SAR with the standard values of SAR for the whole and localize part of the body given by the ICNIRP and suggest the safety distance for installing GSM mast.

\section{MATERIALS AND METHODS}

Study Area: Mubi is the second largest city in Adamawa State; it has many GSM masts installed on different streets. This research considered the GSM mast installed in this area (Lukuwa) because of the several institutions situated there. These include; Adamawa State University, Federal Polytechnic, Collage of Health, Government Secondary School, Government Technical College and Mundra Model School to mention but few. Students spend most of their time in this area and it will be useful to investigate the radiation of this area. Point to point communication is achieved by using GSM mast usually installed in the residential 
areas. These antennas are mounted on mast roughly above the ground level; they are mostly circular in shape and are made to radiate power density when transmitting signals. The antenna parameters installed at the study area are summarized as given in Table 1

Table 1: Standard Parameters, for GSM

Mast Installed at Lukuwa, Mubi.

\begin{tabular}{ll}
\hline \multicolumn{1}{c}{ Parameters } & \multicolumn{1}{c}{ Specification } \\
\hline Transmitter's Gain & $45(\mathrm{dBm})$ \\
GSM Mast Height & $30-40(\mathrm{~m})$ \\
Carrier Frequency & $900 / 1800(\mathrm{MHz})$ \\
Bandwidth & Broadband \\
VSWR & $2: 1$ \\
H-Plane Beam & Omni Directional \\
Width & \\
E-Plane Beam & 100 degree \\
Width & \\
Polarization & Vertical \\
Operational & -20 to $+60^{\circ} \mathrm{C}$ \\
Temperature & \\
Storage & -30 to $+75^{\circ} \mathrm{C}$ \\
Temperature & \\
\hline
\end{tabular}

The materials used in this work are as followed: Measuring Tape, Table, GSM Mast and Electromagnetic Meter. The Electromagnetic Meter has the following features (Data Memory, Audible Pulse Ticker, Audio Warning Alert, Dosage Expose Chart, Muti-Function Key parts and Digital Display) was placed on a table of $1 \mathrm{~m}$ height away from foot of GSM mast throughout the measurement, in order to measure the power density at a specific distance (D). The measuring tape was used to measure the distance required between the foot of the table and the GSM mast. These measurements are carried out in two phases.

- The measurement of the power density was conducted at different distances $(10 \mathrm{~m}-50 \mathrm{~m})$ for 7

Method of Data Analysis: Fuzzy Logic and Specific Absorption Rate: Fuzzy logic simulation model is developed to predict the total amount of the power density measured since the measurements are carried out in two different phases and SAR level will be computed from the predicted power density.

Fuzzy logic is a modelling and computing tool, usually developed based on the "degree of truth" (Zedah, 1965) rather than the normal Boolean logic ( 0 or 1$)$ generally used in modern computer. The 0 days, which is considered as initial power density (P) measured. After a week, the measurement was repeated at the same distances for another 7 days, considered as the new power density (B) measured.

These separate measurements were conducted to enable the expert formulate the fuzzy rules. The average values of the power densities measured are summarized in Table 2 and, are also presented in Fig. 1.

Table 2: Initial and New Power Density Measured

\begin{tabular}{lll}
\hline $\mathbf{D}(\mathbf{m})$ & $\mathbf{P}\left(\boldsymbol{\mu} \mathbf{W m}^{-\mathbf{1}}\right)$ & $\mathbf{B}\left(\boldsymbol{\mu} \mathbf{W m}^{-1}\right)$ \\
\hline $\mathbf{1 0}$ & 36.96 & 37.16 \\
$\mathbf{1 5}$ & 13.02 & 02.52 \\
$\mathbf{2 0}$ & 08.76 & 09.29 \\
$\mathbf{2 5}$ & 07.03 & 07.49 \\
$\mathbf{3 0}$ & 06.58 & 06.13 \\
$\mathbf{3 5}$ & 02.95 & 03.03 \\
$\mathbf{4 0}$ & 01.97 & 02.00 \\
$\mathbf{4 5}$ & 01.67 & 01.78 \\
$\mathbf{5 0}$ & 02.20 & 02.32 \\
\hline
\end{tabular}

From Fig. 1, it can be seen that, as the distance (D) increases, the power densities decreases ( $P$ and B).

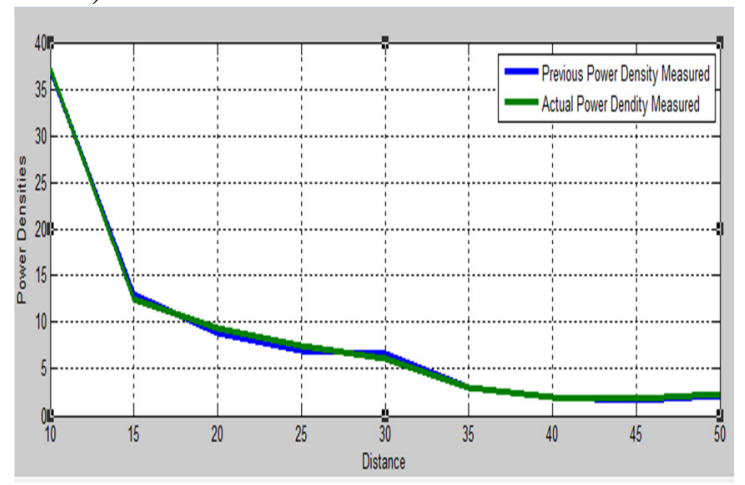

Fig. 1: Power Densities against Distance

or 1 are considered in fuzzy logic as the "extreme cases of truth" which means numbers can exist between them. For example, power density measured or radiated from the GSM mast may be classified as low, moderate or high radiation. In fuzzy logic technique, relationship can exist between low, moderate or high radiation. Fuzzy logic can be employed to solve indispensible problems, like prediction of future occurrence of an event driven from the previous or present information. In order to realize the implementation of the fuzzy logic procedures, Fig. 2 will be utilized. 


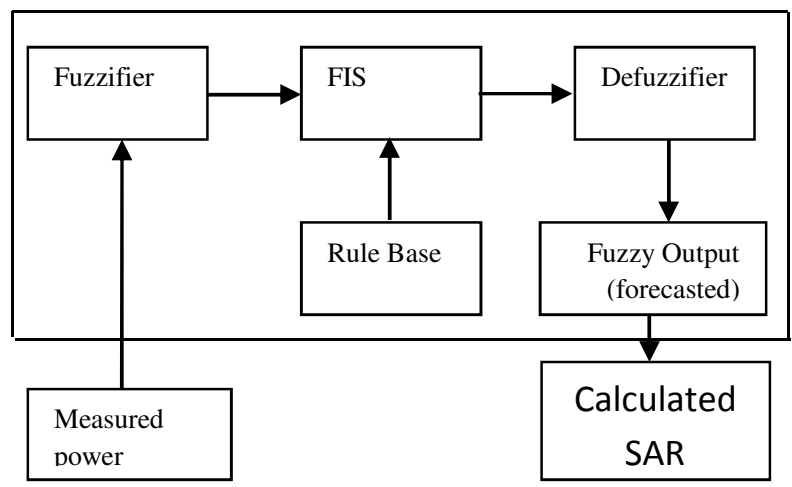

Fig 2: Block diagram of fuzzy logic procedure.

As shown in Fig. 2. Firstly, the inputs (power density and distance) are fuzzified and sent to the Fuzzy Inference System (FIS), plus the fuzzy rules developed by an expert(s). Secondly, the rule acts on the fuzzified inputs in the FIS and gives an output. Thirdly, the output of the FIS is defuzzified to produce the required output.

Fuzzification of Input and Output Data: The first step to take into cognizance using fuzzy logic models is to fuzzify the input and output. Usually, the input/output are fuzzified based on the data range (maximum and minimum) for defuzzification to be realised (Farzaneh, 2010 and Franck, 2013).

Classification of Input and Output Data: The distance (D), initial power density (P) and new power density (B) are classified as follows: short distance SD (2-15m), medium distance MD (1440m), long distance LD (35-63m), low initial power density: LP $\left(1-13.5 \mu \mathrm{W} / \mathrm{m}^{2}\right)$, average initial power density AP $\left(3.5-15 \mu \mathrm{W} / \mathrm{m}^{2}\right)$, high initial power density HP $\left(11-60 \mu \mathrm{W} / \mathrm{m}^{2}\right)$. Also, low new power density LB $\left(3.5-15 \mu \mathrm{W} / \mathrm{m}^{2}\right)$, average new power density $A B\left(3.5-15 \mu \mathrm{W} / \mathrm{m}^{2}\right)$ and high new power density HB $\left(11-60 \mu \mathrm{W} / \mathrm{m}^{2}\right)$.

Membership Function (MF): Membership function is a graph that defined how input and output are mapped between 0 and1. MF may be classified into mainly two sub-classes: continuous (triangular, gbell, trapezoidal,
Gaussian and piecewise) and discrete (generic singleton and singleton). In this work, triangular would be adopted. This is chosen because of its flexibility on all kinds of data. It's consist of a vector say $r$, and three parameters namely a, b, c, where a and c locate the lower limits, b locates the upper limit of the triangular $\mathrm{MF}$ and $\mathrm{f}$ is function of the variables $(r, a, b, c)$ given by

f $\quad\left(\mathrm{r} ; \quad \mathrm{a}, \quad \mathrm{b}, \quad\right.$ c) $=\left[\begin{array}{lr}0, & x \leq a \\ \frac{x-a}{b-a}, \mathrm{a} \leq x \leq \mathrm{b} \\ \frac{c-x}{c-b}, & b \leq x \leq c \\ 0, & c \leq x\end{array}\right]$

Whereas, the MATLAB syntax may be written as

$r=\operatorname{trim} f(r,[a, b, c])$.

Table $3-5$ give the summary of the linguistic terms and MF intervals of the distance, initial and new power density measured respectively.

Table 3: Linguistic terms and intervals for $\mathrm{MF}$ of distance

\begin{tabular}{|c|c|c|c|}
\hline $\begin{array}{c}\text { Linguistic } \\
\text { Term }\end{array}$ & \multicolumn{3}{|c|}{ Interval } \\
\cline { 2 - 4 } & $\mathbf{a}$ & $\mathbf{b}$ & $\mathbf{c}$ \\
\hline SD & 2.103 & 9.577 & 14.90 \\
\hline MD & 14.00 & 25.67 & 39.89 \\
\hline LD & 34.46 & 47.41 & 63.23 \\
\hline
\end{tabular}

Table 4: Linguistic terms and intervals for MF of power density measured

\begin{tabular}{|c|c|c|c|}
\hline \multirow{2}{*}{$\begin{array}{c}\text { Linguistic } \\
\text { Term }\end{array}$} & \multicolumn{3}{|c|}{ Interval } \\
\cline { 2 - 4 } & $\mathbf{a}$ & $\mathbf{b}$ & $\mathbf{c}$ \\
\hline LP & 1.000 & 2.686 & 3.500 \\
\hline MP & 3.500 & 9.429 & 15.00 \\
\hline
\end{tabular}




\begin{tabular}{|l|l|l|l|}
\hline HP & 11.00 & 47.00 & 60.00 \\
\hline
\end{tabular}

Table 5: Linguistic terms and intervals for MF of actual power density measured

\begin{tabular}{|c|c|c|c|}
\hline Linguistic & \multicolumn{3}{|c|}{ Interval } \\
\cline { 2 - 4 } Term & $\mathbf{a}$ & $\mathbf{b}$ & $\mathbf{c}$ \\
\hline LP & 1.000 & 2.686 & 3.500 \\
\hline MP & 3.500 & 9.429 & 15.00 \\
\hline HP & 11.00 & 47.00 & 60.00 \\
\hline
\end{tabular}

Formation of Fuzzy Rule Base: This is an important aspect of fuzzy logic. The rules determine how fit is the prediction. The rule is achieved using IF-THEN conditions using any of the following operators; AND, OR or NOT. In set theory, the relationship between P and D may be written formally as

$$
P \cap D=\{R: R \in P \cap R \in D\}
$$

Similarly, the union of the sets can be expressed as

$$
P \bigcup D=\{R: R \in P \bigcup R \in D\}
$$

While, In fuzzy logic, $R \in P \cap D$ iff, $R \in A$ and $A$ stands as the universal set of $P$ and D. Equation (3) and (4) are transformed based on fuzzy operators as given in (5) and (6)

$$
\begin{aligned}
& \mu P \cap \mu D(A)=\min \{\mu P(A), \mu D(D)\}, \text { 圆 } \\
& \mu P \bigcup \mu D(A)=\max \{\mu P(A), \mu D(D)\}, \text { ? }
\end{aligned}
$$

Based on expression (5) or (6), the fuzzy rules would be developed, where $\mu_{\mathrm{P}}, \mu_{\mathrm{B}}$ and $\mu_{\mathrm{D}}$ are the MF of the initial and the new power density measured with the MF of their corresponding distances.

The rules were formed as follows

1. If (distance is SD) AND (power density is HP), then (actual power density is HB).

2. If (distance is $\mathrm{AD}$ ) and (power density is MP), then (actual power density is $\mathrm{AB}$ ).

3. If (distance is LD) and (power density is LP), then (actual power density is LB).

Fuzzy Logic Simulation Model

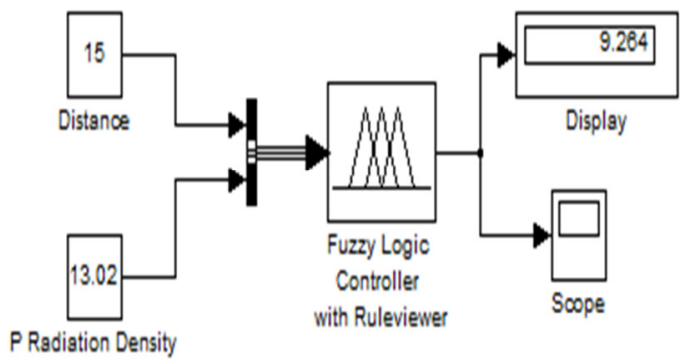

Fig 3: Fuzzy Logic Simulation Model

The block diagram shown in Fig. (2), can be transformed into the simulation model of the fuzzy logic depicted in Fig. (3). The model incorporates, two Constants (inputs), Multiplexer which multiplex's the inputs, Fuzzy Logic Controller with Ruleviewer, Display and Scope. The input data is randomly selected from the sets of the sample data collected. For example, $\mathrm{P}=$ $13.02 \mu \mathrm{Wm}^{-1}$ at $\mathrm{D}=15 \mathrm{~m}$. After simulation the power density predicted is shown on the display as $9.26 \mu \mathrm{Wm}^{-1}$ in Fig. (3) and it is also indicated on the rule viewer in Fig. (4). 


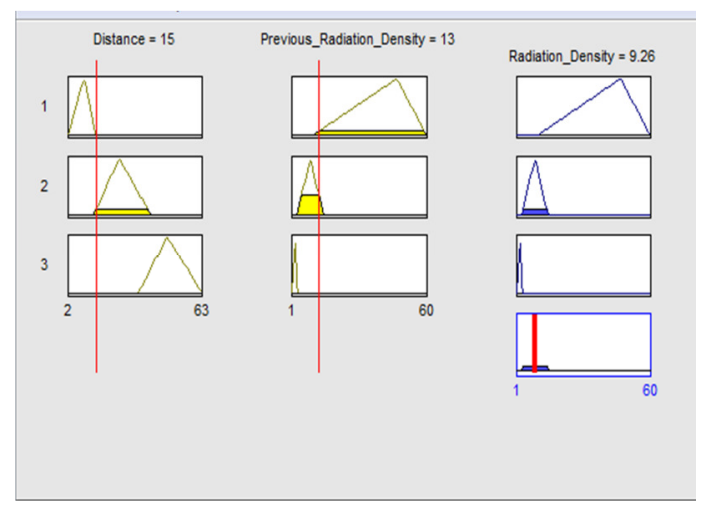

Fig 4: Defuzzified (predicted output of one sample data)

Error Analysis: The measure of the prediction accuracy is considered using absolute percentage error (APE) and mean absolute percentage error (MAPE), as given in Equation (7) and (8).

$\mathrm{APE}=\frac{\mid \text { actual }- \text { forecast } \mid}{\text { actual }} \times 100 \%$

$\mathrm{MAPE}=\frac{1}{n} \sum_{i=1}^{n}\left|\frac{\text { actual }- \text { forecast }}{\text { actual }}\right| \times 100 \%$

Power Density and Specific Absorption Rate: Theoretically, power density comprises of electric field, E and magnetic field, $\mathrm{H}$. Usually, obtained from poynting theorem, given by

$$
P=(E \times H)
$$

Where the total electric field and the total magnetic field are related as given in (10)

$$
\frac{E}{H}=\sqrt{\frac{\mu}{\varepsilon}}
$$

Equation, (10) has the dimension of impedance measured in ohms, which is called the characteristic impedance designated by $\mathrm{Z}$, as given in (11).

$$
Z=\frac{E}{H}=\sqrt{\frac{\mu}{\varepsilon}}
$$

For any medium, whether conducting or not, the characteristic impedance of a free space may be $\mathrm{Z}=$ $\mathrm{Z}_{0}, \mu=\mu_{0}$ and $\varepsilon=\varepsilon_{0}$. Therefore, Equation (12) becomes
$Z_{0}=\sqrt{\frac{\mu_{0}}{\varepsilon_{0}}}=120 \pi=377 \Omega$

Where, $\mu_{0}$ is the permittivity of free space and $\varepsilon_{0}$ is the permeability of free space. The power density measured from GSM mast may be evaluated using Equation (13).

$$
P_{0}=\frac{E^{2}}{Z_{0}}
$$

The electric field, E takes all it components in $\mathrm{x}, \mathrm{y}, \mathrm{z}$ plane as

$$
E^{2}=E_{x}^{2}+E_{y}^{2}+E_{z}^{2}
$$

In order to, determine the specific absorption rate (SAR), Equation (15) is applied.

$$
\operatorname{SAR}(\beta)=\sigma \frac{E^{2}}{\rho}=c \frac{d T}{d t}, t \rightarrow 0
$$

Assuming that, the temperature (T) effect and the specific heat capacity (c) are neglected. The SAR level is obtained by combining (13) and (15) as given in expression (16).

$\beta=\frac{377 \sigma P_{0}}{\rho}$

Where $\sigma$, is the conductivity measured in $\left(\Omega^{-1} m^{-1}\right), \mathrm{P}_{0}$, is the power density measured from the GSM mast and $\rho$, is the mass density in $\left(\mathrm{kgm}^{-3}\right)$.

Equation (16), defines the rate at which radiation energy is absorbed by human or animal body, when exposed to the Radio Frequency (RF) which may consequently destroy tissues or organs in human body (Shalangwa, 2011; Mushtaq and Vijay, 2013). And can be used to calculate specific absorption rate of localize and whole part of the body.

\section{RESULTS AND DISCUSSION}

Fuzzy Sets and MF for Input and Output Variables: Fig. 5 - 7, present the MF of the distance, initial and new power densities measured respectively. In all cases, the first, second and third bigger triangles of the MFs provide information about (SD, LP, LB), (MD, 
MP, $\mathrm{AB}$ ), and (LD, HP, HB) described in terms of $(a, b, c)$ as previously indicated in Table $3-5$, respectively. In addition, the smaller triangles at the base of the bigger triangles are formed when the bigger triangles overlap, which define the degree of truth or intersections between the bigger triangles given as $\mathrm{SD} \cap \mathrm{MD}, \mathrm{MD} \cap \mathrm{LD}$, $\mathrm{LP} \cap \mathrm{MP}, \mathrm{MP} \cap \mathrm{HP}, \mathrm{LB} \cap \mathrm{AB}$ and $\mathrm{AB} \cap \mathrm{HB}$ and these relationships range as follow $14.1-14.9$ $\mathrm{m}, 35.1-39.9 \mathrm{~m}, 11.1-14.9 \mu \mathrm{W} / \mathrm{m}^{2}, 3.6-13.4$ $\mu \mathrm{W} / \mathrm{m}^{2}, 11.1-14.9 \mu \mathrm{W} / \mathrm{m}^{2}$ and $3.6-13.4$ $\mu \mathrm{W} / \mathrm{m}^{2}$ based on the scale chosen for a particular $\mathrm{MF}$, respectively. These are information used to facilitate the formation of the fuzzy rules in Equation (5).

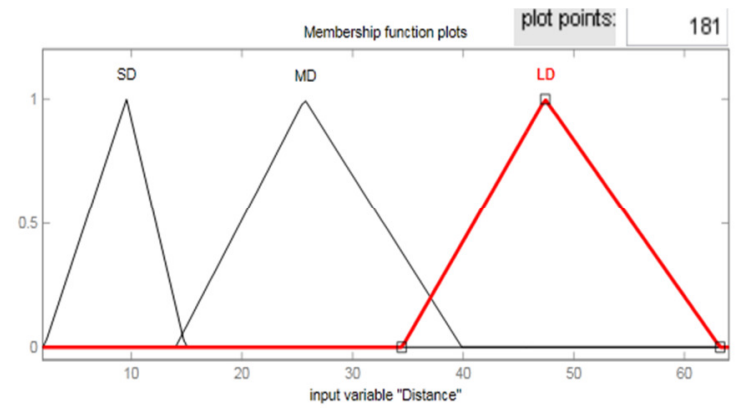

Fig 5: MF of the Distance

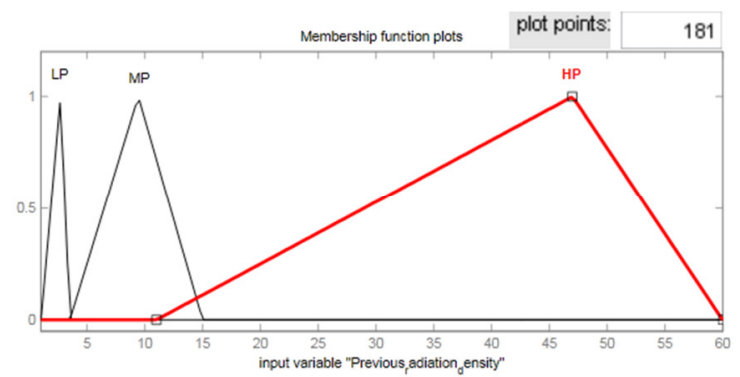

Fig 6: MF of the new power density measured

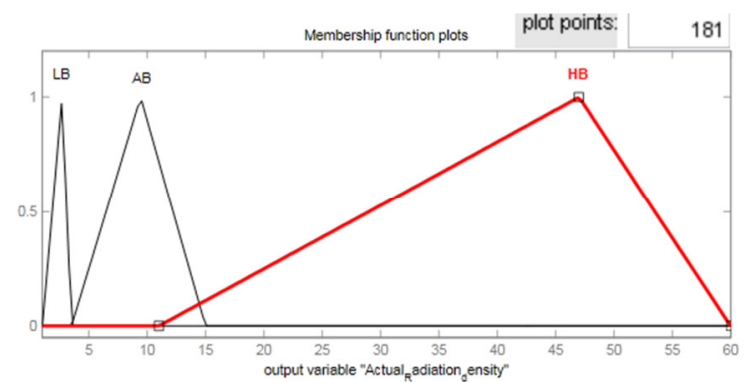

Fig 7: MF of initial power density measured.

As earlier stated, fuzzy logic model is developed to predict the amount of power density measured. At $10 \mathrm{~m}, 20 \mathrm{~m}, 25 \mathrm{~m}, 30 \mathrm{~m}, 40 \mathrm{~m}, 45 \mathrm{~m}$ and $50 \mathrm{~m}$, the predicted power density is greater than the initial power densities measured by $1.94 \mu \mathrm{Wm}^{-1}$,
$0.54 \mu \mathrm{Wm}^{-1}, 2.26 \mu \mathrm{Wm}^{-1}, 2.71 \mu \mathrm{Wm}^{-1}, 0.41 \mu \mathrm{Wm}^{-1}$, $0.7 \mu \mathrm{Wm}^{-1}, 0.16 \mu \mathrm{Wm}^{-1}$ and greater than the new power density measured by $1.74 \mu \mathrm{Wm}^{-1}, 0.01 \mu \mathrm{Wm}^{-1}$, $1.80 \mu \mathrm{Wm}^{-1}, 3.16 \mu \mathrm{Wm}^{-1}, 0.38 \mu \mathrm{Wm}^{-1}, 0.59 \mu \mathrm{Wm}^{-1}$, $0.04 \mu \mathrm{Wm}^{-1}$ respectively as shown in Fig. (8), While, their corresponding SAR $(\beta)$ level computed from the predicted power density using Equation (16) are obtained as $1.09 \mathrm{e}^{-4} \mathrm{~W} / \mathrm{Kg}, 2.62 \mathrm{e}^{-5} \mathrm{~W} / \mathrm{Kg}$, $2.61 \mathrm{e}^{-5} \mathrm{~W} / \mathrm{Kg}, \quad 2.61 \mathrm{e}^{-5} \mathrm{~W} / \mathrm{Kg}, \quad 6.69 \mathrm{e}^{-6} \mathrm{~W} / \mathrm{Kg}, \quad 6.66 \mathrm{e}^{-6}$ $\mathrm{W} / \mathrm{Kg}, 6.63 \mathrm{e}^{-6} \mathrm{~W} / \mathrm{Kg}$. However, it is observed in two peculiar cases, at $15 \mathrm{~m}, 35 \mathrm{~m}$ the predicted power density is less than the initial and the new power density measured by $3.76 \mu \mathrm{Wm}^{-1}, 0.48 \mu \mathrm{Wm}^{-1}$ and $3.26 \mu \mathrm{Wm}^{-1}, 0.56 \mu \mathrm{Wm}^{-1}$ with their corresponding $\mathrm{SAR}$ levels as $2.60 \mathrm{e}^{-5} \mathrm{~W} / \mathrm{Kg}, \quad 6.94 \mathrm{e}^{-6} \mathrm{~W} / \mathrm{Kg}$ respectively. In general, it is observed that, the SAR level reduced by $\mathrm{x} 10$ when distance increase in every $15 \mathrm{~m}$. Furthermore, the MAPE is determined as $19.87 \%$ from Equation (8) and model efficiency is validated as $80.13 \%$ and it is also, observed that, at $40 \mathrm{~m}, 45 \mathrm{~m}$ and $50 \mathrm{~m}$, the forecasted power density increased by $0.01 \mu \mathrm{Wm}^{-1}$, while its corresponding $\mathrm{SAR}$ reduced by $0.03 \mathrm{e}^{-6} \mathrm{~W} / \mathrm{Kg}$.

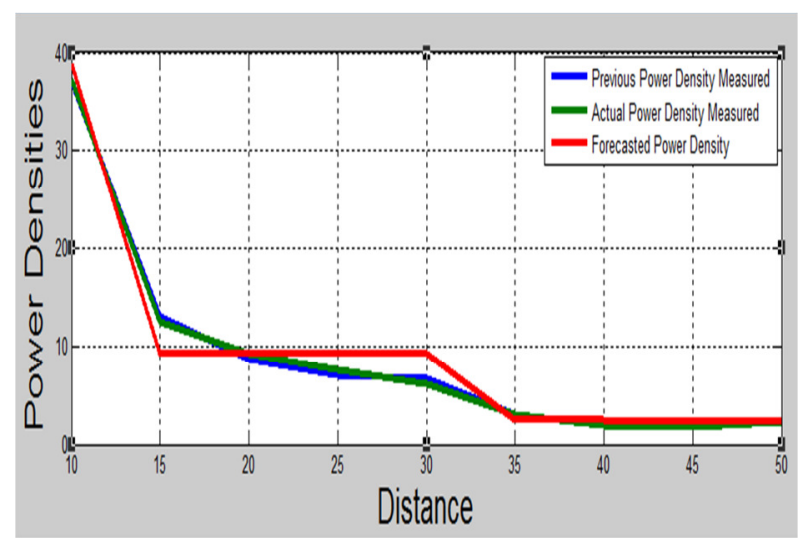

Fig 8: Power Densities vs Distance

In addition, all the power densities followed almost the same pattern, as the distance increases; the radiation reduces as previously mentioned. Although, the forecasted power density seems to be constant from $15 \mathrm{~m}-30 \mathrm{~m}$

Comparison between the calculated and the Standard SAR Level: The maximum SAR level calculated is $1.09 \times 10^{-4} \mathrm{~W} / \mathrm{Kg}$ at $10 \mathrm{~m}$, this value is compared with the standard values of the SAR level of the localize $(10 \mathrm{~g} /$ tissue $)$ and whole part of the body given by $2.00 \mathrm{~W} / \mathrm{Kg}$ and $0.08 \mathrm{~W} / \mathrm{Kg}$, respectively as depicted in Fig. (9), and found to be far below recommended level. Therefore, this work, suggests that, $10 \mathrm{~m}$ is a good distance for installing GSM mast away from residential areas because, the SAR level obtained at this distance is $99 \%$ safe, far 
less than the standard values $\left(1.09 \times 10^{-4} . \mathrm{Kg} / \mathrm{W}<<\right.$ 0.08 or $\left.1.09 \times 10^{-4} . \mathrm{Kg} / \mathrm{W}<<2.00 \mathrm{Kg} / \mathrm{W}\right)$.

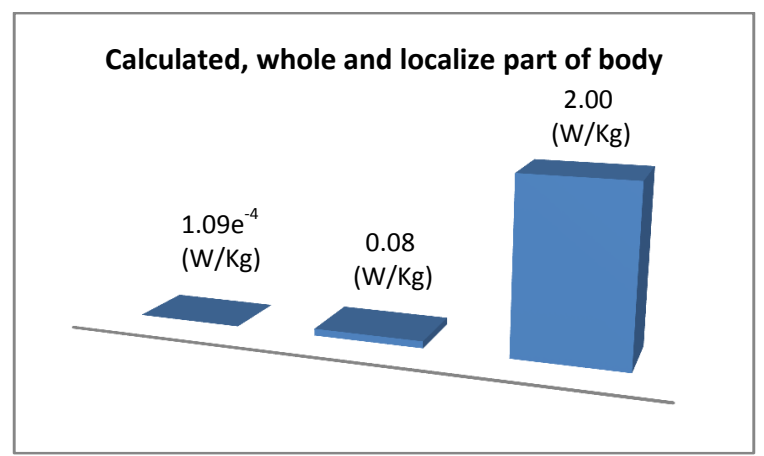

Fig 9: SAR levels

Conclusion: Despite the fact that, the introduction of GSM technology has tremendously solved the problem of telecommunication in Nigeria, the health implication of power density radiated from GSM phones or mast installed in residential areas has become an issue of concern amount Nigerians. This work, utilized fuzzy logic technique to forecast the power density radiated from the GSM mast and SAR level is computed from power density measured. Based on SAR level obtained, it is recommended that, $10 \mathrm{~m}$ is a good distance for installation of GSM mast in residential area in Nigeria. In addition, it is suggested that, multi-disciplinary research should be carried out to ensure more positive result.

\section{REFERENCES}

Akintola, A; Busari, AA; Awodele, O; Olayemi SO (2009). The Hazards of Non-Ionizing Radiation of Telecommunication Mast in an Urban Area of Lagos, Nigeria. Afric. J Biomed. Res. 12(1):31-35.

Dariusz, L; Sakari, J; Jukka, R; Reetta, K (2002). Non Thermal Activation of the hsp27/p38 MAPK Stress Pathway by Mobile Phone Radiation in Human Endothelial Cells, Molecular Mechanism for Cancer and Blood Barrier Related Effects" Blackwell Verlay Publishers, 70:120 - 129 .

Farzaneh A, (2010). Computational Intelligence Lecture 7 Fuzzifiers and Defuzzifier Fall.

Hyland, GJ (2000). How Exposure to GSM Base Station Radiation can Adversely Affects Human. Department of Physics International Institute of Biophysics University of Warwick Neuss - Helzheim Coventry, 1200 - 1421
ICNIRP, (2009). Summary of the ICNIPR's General Public Safety Guide Lines for Limiting Radiation Exposure and SAR. Available on http//:www.ICNIRP.com

Leif, SA; Jacob, E; Lars, LEM; Bertil, R; Persson, R (2003). Nerve Cell Damage in Mammalian Brain after Exposure to Microwave Phone. $J$. Environ. Health Perspective, 7:881-883.

Lennart, H; Michael, C; Fredric, S; Kjell, HM; Morgan, L (2007). Long Term Used of Cellular Mobile Phone and Brain Tumor; Increased Risk Associated with Use Greater or Equal to 10 Years. J. Occupational Environ. Med, 64 (9): 15

Loan, EM; Claudiu, P (2016). Assessment of GSM HF-Radiation Impact Levels within the Residential Area of Craiova City. Procedia Environ. Sci., 177 - 185

Mamilus, AA; Anthoney, NN (2012). GSM Base Station Radiation Level: A Case Study of University of Nigeria Environment" Int. J. Sci. Technol. Res., 8:102 - 107

Mushtaq, AB; Vijay, K ((2013). Calculation of SAR and Measurement of Temperature Change of Human Head due to Mobile Phone Waves at Frequencies $900 \mathrm{MHz}$ and 1800MHz. Advaves in Phy. Theo. Application, 16:1 - 10.

Persson, BRR (1997). Blood Brain Barrier Permeability in Rats Exposed to Electromagnetic Fields used in Wireless Communication and Wireless Network. Kluwer Academic Publishers 461 Hingham. MA USA: 455.

Qing, Qing; HeWan, Chun Yang; Yan Xia, Hu (2014). Accurate Method to Estimate EM Radiation from a GSM Base Station. Progress. Electromagnetic Res. M, 34:10 27

Sahar, AA; Jabir, SA (2013). SAR Simulation in Human Head Exposed to RF Signals and Safety Precautions. 3(9). Available online @ www.ijcset.net

Santini, R; Santini, P; Danze, JM; LeRuz, P; Seigne, M (2003). Survey Study of People Living in the Vicinity of Cellular Phone Base Stations. Electromagnetic Biology and Medicine. 
http://www.informaworld.com/smpp/content contentRa713628949

Shalangwa, DA (2010). Measurement of Exposure of Radio Frequency Field (RF) Radiation from Global System for Mobile Communication (GSM) Mast. J. Elec. Elec. Eng. Res., 3:75 84

Shalangwa, DA (2011). Review of Residential Exposure from Radio Frequency (RF) of Global System for Mobile Communication (GSM) Base Station (BS). SENRA Academic publishers, Burnaby, British Columbia 5(1): $1405-1411$

Shangchen, X; Leizhangy, XW; Maoquan, L; Chunbai, C; Mindi, H; Guangbin, Z; Zhenping, Y (2009). Exposure to $1800 \mathrm{MHz}$ Radio Frequency Radiation Induces Oxidative Damage to Mitochondrial DNA in Primary Cultured Neutrons. Science Direct, 4: 1-8
Thomas, H; Uwe, M; Peter, S (2002). Nonstop Pulsed Radiation Inside Home. 2nd Int. Workshop on Biological Effects Electromagnetic Fields, 775 - 780.

Zadeh, LA (1965). Fuzzy Sets, Information and Control. J. Symtotic Logic. 8(7): 1 - 16 